\title{
Belgique, Marseillaise et Brabançonne
}

Belgium, Marseillaise and Brabançonne

DOI: 10.20396/rhac.vli2.14338

BERNARD RICHARD

Agrégé d'histoire, ancien enseignant dans les universités de Rabat et de Paris X - Nanterre puis attaché culturel en Amérique latine et en Egypte

\section{Résumé}

Les Belges ont entendu et souvent entonnée la Marseillaise sous la Révolution française. C'est encore au son d l'hymne français qu'ils se révoltent en août 1830, quand ils créent leur drapeau tricolore et leur hymne, la Brabançonne. Avec la Grande Guerre de 1914-18, ils accueillent l'armée libératrice en chantant encore la Marseillaise de préférence à leur propre hymne parfois. Ils l'entendent encore sur les stades et même dans la bouche d'un de leur grands hommes politiques, confondue avec la Brabançonne par ce politique en 2007. La Marseillaise fait presque parti du patrimoine belge.

Palavras-chave: Belgique. Marsellaise. Brabançonne. Iconographie nationale.

\begin{abstract}
The Belgians heard and often sang the Marseillaise during the French Revolution. It was still to the sound of the French anthem that they revolted in August 1830, when they created their tricolor and their hymn, the Brabançonne. With the Great War of 1914-18, they welcomed the liberating army by still singing the Marseillaise in preference to their own anthem sometimes. They still hear it in the stadiums and even in the mouth of one of their great politicians, confused with the Brabançonne by this politician in 2007. The Marseillaise is almost part of Belgian heritage.
\end{abstract}

Keywords: Belgium. Marseillaise. Brabançonne. National iconography. 
Des Belges ont pu entendre la Marseillaise au moins dès le 6 novembre 1792, quand le général Dumouriez la fit entonner par ses troupes pour charger les Autrichiens à la bataille de Jemmapes (ou Jemappes, écrit-on encore) ; et c'est «en fanfare» que les troupes françaises entrèrent le 14 novembre dans Bruxelles, sans doute au son de la même marche qui venait de leur offrir la victoire. Le territoire, bientôt perdu puis reconquis (par la bataille de Fleurus, 26 juin 1794), formait auparavant et depuis 171314 les «Pays-Bas autrichiens », placés sous la souveraineté des Habsbourg. Devenue bientôt une partie de la République française puis de l'Empire des Français, cette région est intégrée en 1815 dans le « royaume uni des Pays-Bas » attribué par le Congrès de Vienne en 1815 à Guillaume ler d'Orange-Nassau.

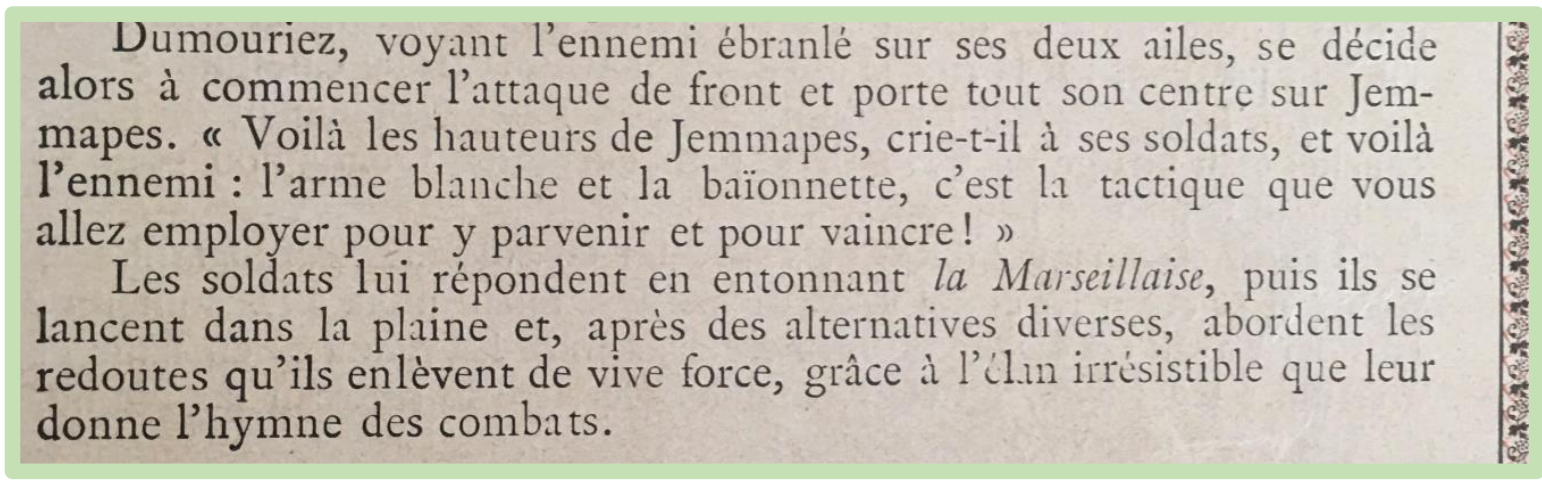

Figure 1 : Couvre-cahier d'écolier. Belgique, vers 1920 (coll. de l'auteur).

Xavier Maugendre, dans L'Europe des hymnes, sans que sa source soit vraiment assurée, décrit ainsi la place importante occupée par l'hymne en février 1796 :

Le rédacteur de Bruxelles, sous la plume de Norbert Cornelissen, ne tarit pas d'éloges envers notre hymne. II l'a entendu à Rome, Florence... Tout ce qui, en ce moment, a rapport à La Marseillaise intéresse le public. Il y a de la mauvaise foi à dire qu'on ne chante cet hymne qu'en France. On le chante partout où se trouvent des amis de la liberté.

Si cette source était authentifiée, ce serait là un début prometteur pour la Marseillaise chez les Belges! Ajoutons que bien des cloches d'églises et d'abbayes de Belgique, enlevées sous la Révolution française en application de la législation campanaire républicaine, sonnent aujourd'hui encore dans des lieux de culte en France, étonnante fusion ou confusion sonore toujours active².

\footnotetext{
${ }^{1}$ MAUGENDRE, Xavier. L’Europe des hymnes dans leur contexte historique et musical. Éditions Mardaga : 1996, p. 32.

${ }^{2}$ SUTTER, Éric [président de la Société Française de Campanologie]. La Révolution française et les cloches belges. Patrimoine campanaire, n. 67, supplément, mai 2011, p. 9 et seq. Et du même auteur, un article homonyme et complémentaire publié dans : Bulletin de l'Association Campanaire Wallonne, n. 101, oct. 2020.
} 


\section{L'insurrection belge lancée en août 1830 au son de la Marseillaise}

Tout commence - ou recommence - au Théâtre de la Monnaie à Bruxelles en août 1830 quand le public acclame La Muette de Portici (1828), œuvre du compositeur français Auber dont le livret, écrit par Scribe, relate une insurrection alors célèbre des Napolitains contre la Couronne espagnole au XVII ${ }^{\mathrm{e}}$ siècle. Certaines notes et paroles de l'œuvre sont proches de celles de la Marseillaise dont Auber était un fervent admirateur: «Amour sacré de la patrie [sic] / Rends-nous l'audace et la fierté... ». L'enthousiasme ne cesse de croître au cours des représentations successives, toujours au son d'une Marseillaise entonnée par le public. Le 25 août 1830 la population de Bruxelles, déjà incitée et excitée par l'exemple tout proche de la Révolution de Juillet à Paris, se soulève contre le roi des Pays-Bas Guillaume I ${ }^{\text {er }}$. L'hymne national hollandais donc du royaume uni des Pays-Bas, dit le Guillaume de Nassau et datant de 1572-73, considéré souvent comme le plus ancien hymne du monde ou d'Europe, commençait par « Guillaume de Nassau, je suis de sang allemand et jusqu'à la mort dévoué à mon pays... », déjà une affaire de sang...

L'insurrection commence donc au Théâtre de la Monnaie avant d'être poursuivie par la «rue belge » à Bruxelles puis à Liège, au son de l'hymne français utilisé par les Belges comme chant-fétiche de la liberté, de libération. Parallèlement est créée et lancée fin août la Brabançonne, bientôt devenue I'hymne national belge. Certaines de ses paroles, au départ très agressives à l'encontre des Néerlandais, sont plus tard retouchées et modérées pour contrer des éventuelles visées annexionnistes de Napoléon III et faciliter l'entente entre les deux monarchies constitutionnelles et les deux peuples de Belgique et des Pays-Bas, avec dans le troisième couplet : « ... Belges, Bataves, plus de guerres, / Les peuples libres sont unis.» et en final de chaque couplet, la «triade belge», devise d'ailleurs reprise par trois fois : «Le Roi, la Loi, la Liberté», proclamant trois valeurs sacrées (paroles de Charles Rogier, 1860). La fête nationale belge, instituée fin XIXe siècle, commémore quant à elle le serment prêté le 21 juillet 1831 par le prince allemand devenant Léopold ler, roi des Belges, serment prêté de respecter fidèlement la constitution adoptée avec l'accord des souverains anglais et français.

A partir de fin 1792, donc dès l'année même de sa création, la Marseillaise fit l'objet en France d'œuvres d'art: scènes lyriques, gravures, tableaux, sculptures, etc. Au contraire la Brabançonne dut attendre un siècle avant d'être enfin figurée par une statue de bronze, pérenne, sur une place bruxelloise. Le plus souvent, les partitions de l'hymne belge n'étaient et ne sont illustrées que par une simple image graphique, souvent image du drapeau national aux trois couleurs disposées à la verticale, «à la française » donc, et apparu lui aussi fin août 1830 [Figures 2-4]. 

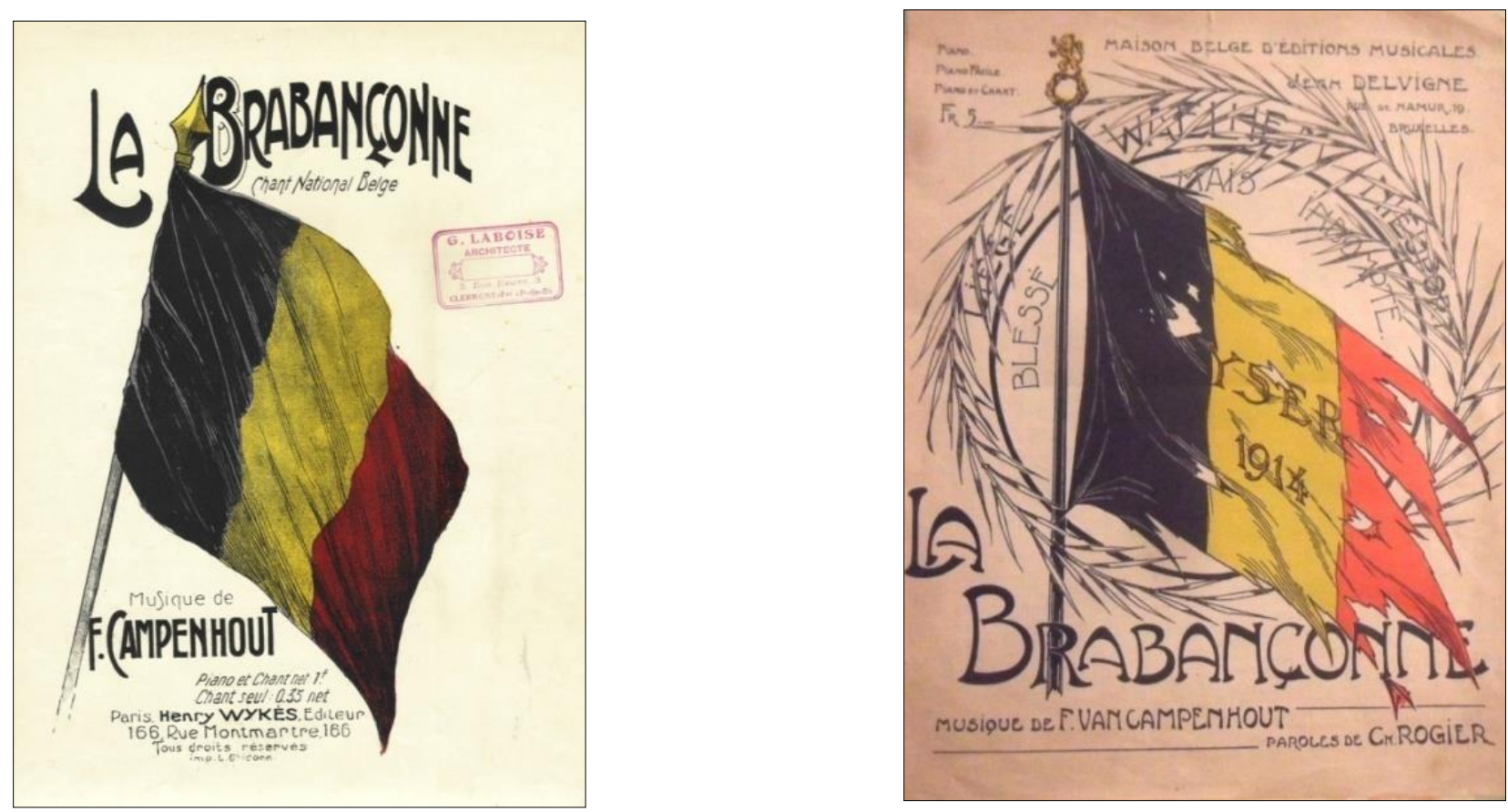

Figure 2: Couvertures de partitions de la Brabançonne, 1910 et 1915 (coll. de l'auteur).

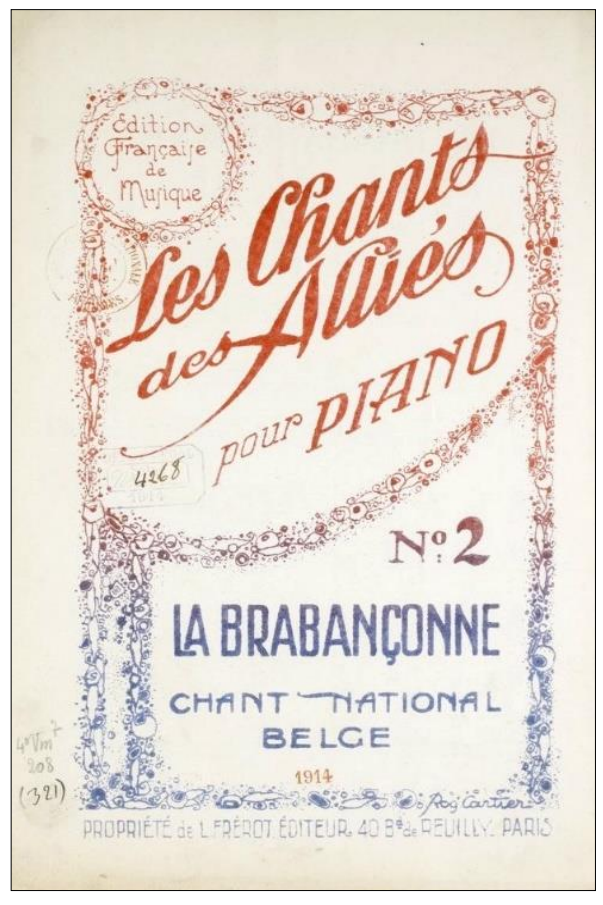

Figure 3:

La Brabançonne: chant national belge. Les Chants des Allies pour piano (couverture d'un arrangement pour piano). Paris : L. Frérot Éditeur, 1914. Bibliothèque nationale de France.

Disponible à :

https://gallica.bnf.fr/ark:/12148/btv1b8594908f Accès à : 17 nov. 2020.

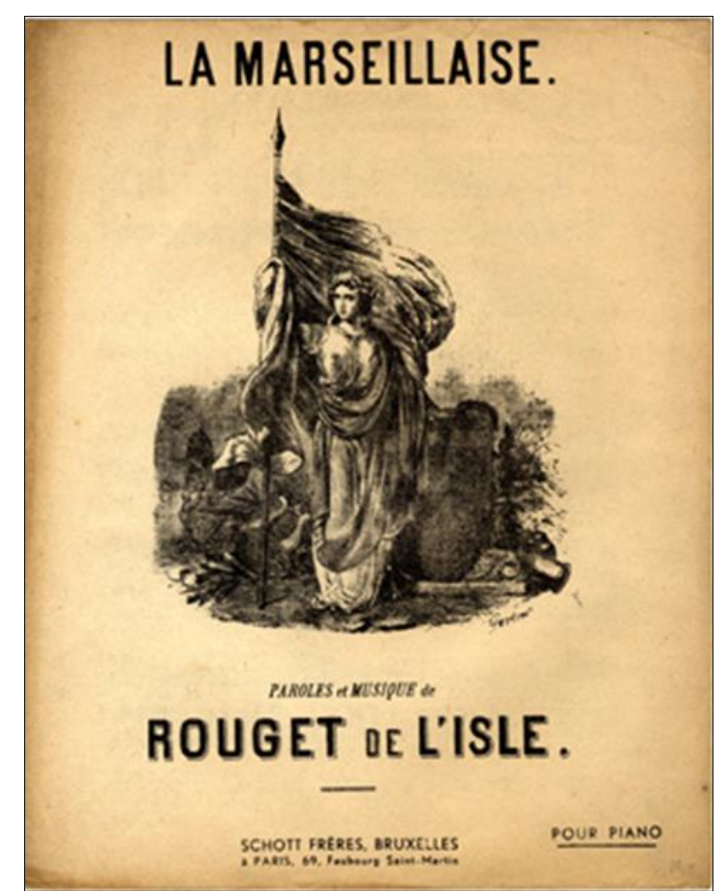

Figure 4:

La Marseillaise : paroles et musique de Rouget de L'Isle (couverture d'un arrangement pour piano). Bruxelles : Éditions Schott Frères. 
La Brabançonne, née à Bruxelles fin août 1830, a modifié ses paroles en grandissant, comme il se doit pour quiconque passe de l'enfance à l'âge adulte. Mais fin 1830 ou début 1831 apparaît une autre chanson d'hommage à l'insurrection; c'est La Bruxelloise, d'un certain Gustave Naquet, sans doute un Français. Elle fut publiée en 1831 à Paris dans un recueil éclectique mais dans l'esprit de la révolution libérale de Juillet 1830 et intitulé L'arc-en-ciel de la Liberté... II fut constitué par le poète E. Debraux, un ami du chansonnier Béranger ${ }^{3}$. Gustave Naquet, auteur inconnu ou méconnu de la Bruxelloise, n'est qu'un homonyme - ou peut-être un parent - de celui qui fut nommé préfet de Marseille en 1870 par Léon Gambetta et qui était né en 1819.

La Bruxelloise, sur l'air de la Marseillaise [sic]

I

Belges ! un cri s'est fait entendre:

Guerre aux tyrans! Armons nos bras !

Que leur trône, réduit en cendre,

S'écroule soudain sous nos pas (bis)

Plus de joug, de liens, d'entraves,

Nos lois, nos droits sont écrasés.

Fûmes-nous jamais des esclaves?

(Refrain)

Grondez, canons, grondez et répandez la mort

Grondez, grondez : un ciel vengeur protège notre effort !

II

Un peuple lâche et fratricide

Ose se lever contre nous!

C'est la liberté qui nous guide,

Il doit succomber à nos coups; (bis)

Pour lui la honte, à nous la gloire!

Bruxelles s'arme et veut...tout fait,

Son peuple fier a tout détruit,

Sa volonté, c'est la victoire!

(au refrain)

III

La France, son émule,

La Belgique a ses défenseurs,

La horde des tyrans recule

Devant ses magiques couleurs. (bis)

$[\ldots]^{4}$

\footnotetext{
${ }^{3}$ NAQUET, Gustave. La Bruxelloise. In : L'arc-en-ciel de la Liberté, ou Couronne lyrique offerte à ses défenseurs : recueil de chansons inspirées par ses meilleurs poètes par nos révolutions et notamment par celle des 27, 28 et 29 juillet 1830 ; suivies de l'Oraison funèbre des braves morts pour la défense de la patrie, recueillies par E. Debraux. Paris: Terry Jeune, Librairie : 1831, p.162-164. Disponible à : https://gallica.bnf.fr/ark:/12148/bpt6k5447751z. Accès à : 17 nov. 2020.

${ }^{4}$ Ibidem.
} 
La Bruxelloise de G. Naquet comporte un total de sept couplets de chacun huit vers auxquels s'ajoute un refrain vengeur ; elle est particulièrement agressive avec les Néerlandais, « un peuple lâche et fratricide... [qui] doit succomber à nos coups ». Emule de la Marseillaise, elle en a accentué la violence...

\title{
Pendant la Grande Guerre, et après
}

Quand la Belgique fut envahie et presqu'entièrement occupée par l'armée allemande, dès août 1914, apparut une partition de la Brabançonne illustrée par une allégorie féminine [Figure 5] à la posture martiale proche des représentations coutumières de la Marseillaise, avec une chanteuse ardente, bouche ouverte et brandissant drapeau et glaive, mais il s'agit du produit momentané des effets ou méfaits de la guerre.

Cette image allégorique datée de 1914 illustre la transformation momentanée de la Brabançonne en jeune compagne armée de la Marseillaise, comme en août 1830. Un poème patriotique du moment intitulé Pour la Patrie proclame d'ailleurs :

\author{
Et, s'exaltant, la Brabançonne \\ Groupe le peuple autour du roi. \\ Sœur de la grande Marseillaise, \\ Qui combattit tant de tyrans, \\ Elle nous crie à la française : \\ «Serrez les rangs!»
}

Et en voici la suite :

\section{La France}

Comme le lierre étreint l'écorce

Sans étouffer le chêne droit,

L'union belge fait la force

D'un petit peuple et d'un grand roi.

Chez vous l'honneur n'est pas à vendre :

Nargue Néron, brave Attila.

Fils, pour t’aimer et te défendre,

La France est là.

Figure 6 : «Pour la Patrie», suite, poème lyrique, auteur anonyme ou non identifié (coll. de l'auteur). 


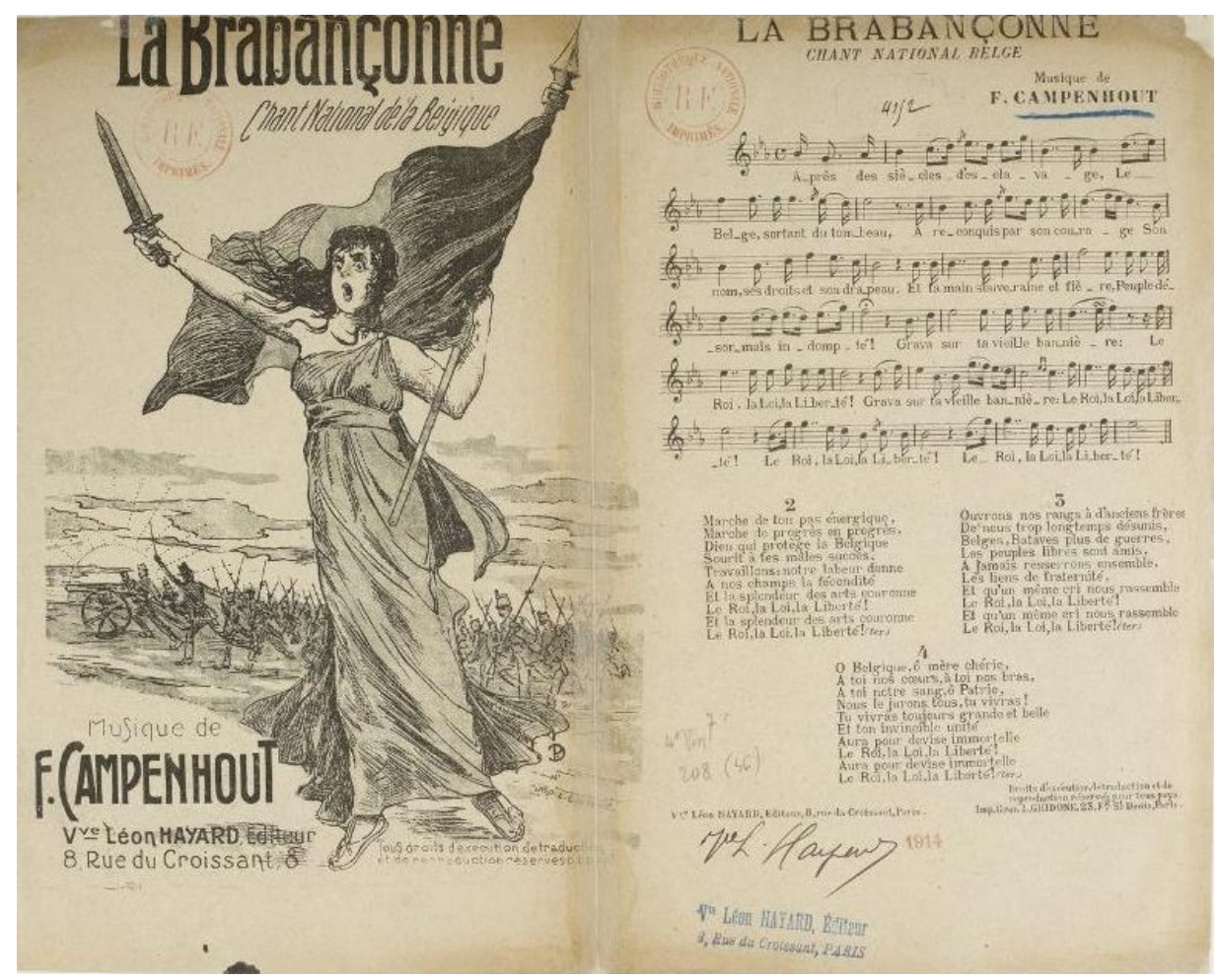

Figure 5:

Allégorie de La Brabançonne. In: La Brabançonne : chant national de la Belgique / musique de F. Campenhout. Partition. Paris : Veuve Léon Hayard, Éditeur, 1914. Bibliothèque nationale de France.

Disponible à : https://gallica.bnf.fr/ark:/12148/btv1b8594942g. Accès à : 17 nov. 2020.
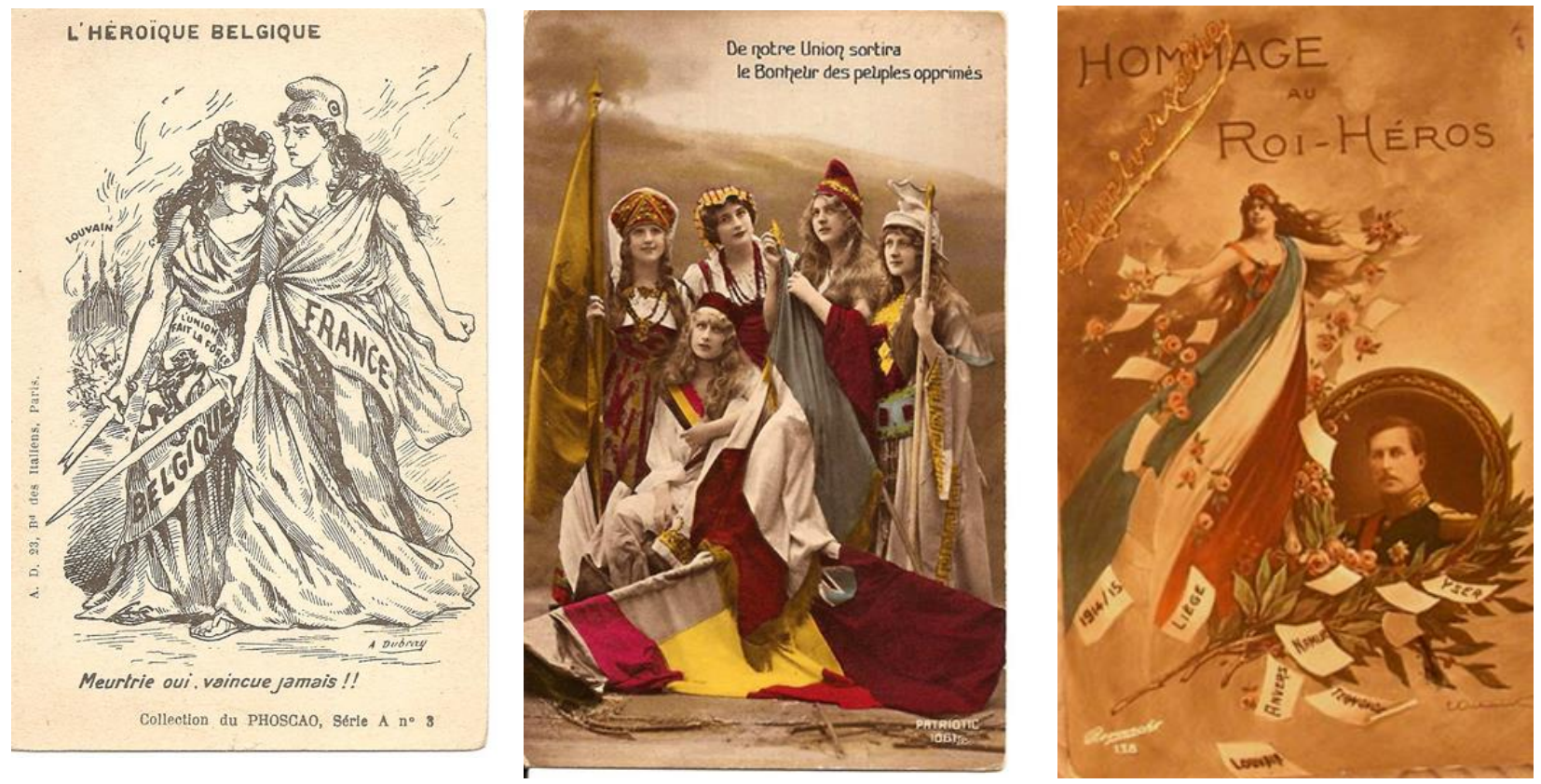

Figure 7: Cartes postales patriotiques (coll. de l'auteur). 
Cependant sur les cartes postales patriotiques [Figure 7] qui fleurissent pendant toute la guerre, la Belgique reste figurée essentiellement par une jeune femme vêtue aux couleurs du drapeau ou coiffée d'une couronnée (car Royaume des Belges), par le drapeau lui-même, par l'uniforme spécifique du soldat belge ou par le portrait du roi Albert $\left.\right|^{\text {er }}$ dit le «roi chevalier », très populaire, mais très rarement par une allégorie féminine de la Brabançonne elle-même.

Pendant la Grande Guerre, un fort courant de sympathie s'épanouit envers la Belgique, son roi, l'épouse de ce dernier, la Reine des Belges Elisabeth, les enfants martyrisés ou mutilés, etc. en France et en Angleterre, avec œuvres littéraires, poèmes, affiches, chansons, pièces de théâtre, caricatures et autre petit matériel de propagande [Figure 8]. Les sentiments réciproques existaient mais ne pouvaient pas s'exprimer tant que la Belgique restait occupée.
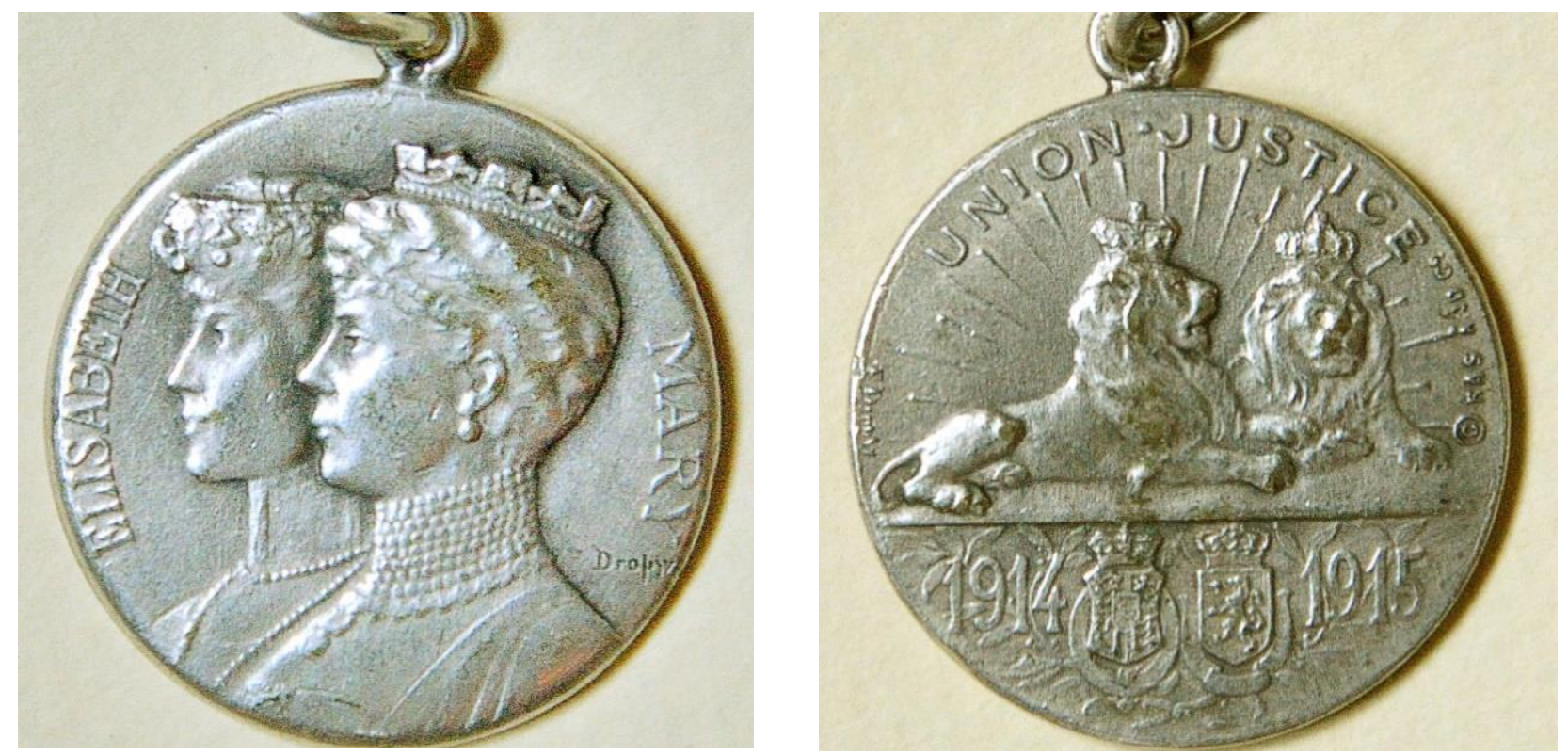

Figure 8: Médaille anglo-belge, avec les deux reines et les lions héraldiques (coll. de l'auteur).

Au hasard de la lecture d'un numéro du Journal de l'Université des Annales, revue grand public très ouverte au «bourrage de crâne» patriotique et littéraire comme le pratique alors l'Académie française, voici la Belgique saluée par un long poème de Jean Richepin, académicien, Le petit drapeau belge, en dix-sept quatrains, ainsi que par le couplet vengeur d'une adaptation de la Carmagnole par le chansonnier Fursy («Les Belges l'ont buté [Guillaume II] / Chantons la Brabançonne, vive le son... »), enfin par un passage d'une biographie de La Fayette par un autre académicien rappelant le rôle du « héros des deux mondes» en 1830 dans le soutien français à l'indépendance belge; l'éloge s'achève par la 
reproduction de deux tableaux contemporains de la guerre en cours exaltant le sacrifice et le courage des Belges $^{5}$. Fin 1918, quand enfin est venue la victoire, des enfants des écoles belges se pressent sur le passage de l'armée française pour lui chanter la Marseillaise avec entrain, avec passion même !

Des lettres recueillies dans la correspondance composant le Fonds Émile et Léa Mauny (correspondance de deux instituteurs du département de l'Yonne ayant échangé plus de mille deux cents lettres pendant la Grande Guerre, l'époux étant mobilisé sur le front et son épouse restée pour diriger leur école) nous servent de guide à propos des échos de la Marseillaise en Belgique en novembre et décembre 1918 :

Toujours en marche vers le Rhin. Partout bon accueil. On croise des chariots surchargés de malles et meubles rentrant au logis. Et par-là dessus une bande d'enfants qui grouillent. À notre passage ils crient: «Vive la France !», « Les Français ! Les Français! ! Des groupes de gamins chantent la Marseillaise fort bien ma foi. ${ }^{6}$

Dans une longue lettre datée du 4 décembre 1918, le soldat Émile Mauny décrit le défilé victorieux de sa division dans les rues de Bruxelles, sous les ovations de la population:

À un endroit une école de filles a groupé son personnel et les élèves. Il y a peut-être deux à trois centaines d'enfants de 5 à 10 ans, toutes bouclées, frisées, toutes blondes et charmantes dans leurs robes habillées. Tout ce petit monde chante la Marseillaise à tue- tête. C'est le plus joli tableau que j'ai vu pendant le défilé. ${ }^{7}$

C'est donc dans le public même que réside le spectacle.

Lettre du 22 décembre 1918 alors qu'Émile est en attente de sa démobilisation à Tirlemont, dans le Brabant flamand (de langue flamande et pourtant, ici aussi, on chante la Marseillaise) :

Il paraît que notre général [le général Bernard Serrigny, commandant la 77e division et qui avait été à Verdun le très dévoué chef d'état-major du général Pétain] a été acclamé par la population de Tirlemont ces jours derniers. C'est aujourd'hui dimanche et en ce moment ( 9 heures du soir), une bande de tout jeunes gens passe en chantant la Marseillaise. Cet engouement des enfants et des jeunes gens pour nos troupes prouve que l'opinion ici est très nettement en notre faveur. On sent que cela est spontané. Évidemment, la victoire y est pour quelque chose, mais malgré tout, les autres [les Allemands] ont été trop sauvages. Ils ont perdu le peu de sympathie qu'on avait peut-être pour eux dans ce pays avant la guerre. ${ }^{8}$

\footnotetext{
${ }^{5}$ JOURNAL DE L'UNIVERSITE DES ANNALES. 9 e année scolaire, 1914-1915, Paris, t. I, n. 10, mai-juin 1915 (incluant un dossier consacré à La Marseillaise).

${ }^{6}$ Lettre du 28 novembre 1918. In: MAUNY, Michel. Emile et Léa: lettres d'un couple d'instituteurs bourguignons dans la tourmente de la grande guerre. Migennes : L'Imprimerie Moutot, 2006.

${ }^{7}$ Lettre du 4 décembre 1918. In : Ibidem.

${ }^{8}$ Lettre du 22 décembre 1918. In : Ibidem.
} 
On peut voir ici une allusion, certes indirecte, au fait que les Flamands eux aussi, bien qu'ils soient de langue d'origine germanique, acclament les Français vainqueurs et n'ont plus de sympathie pour les Allemands.

Peu auparavant, lors de la messe de la victoire célébrée par un Te Deum dans la cathédrale Saints Michel et Gudule de Bruxelles, c'est l'assistance qui, spontanément, entonne la Brabançonne et la Marseillaise ainsi que l'hymne anglais. Là encore le spectacle est joué par le public! La popularité de la Marseillaise en tant que hymne et marque identitaire de l'allié français est alors à son apogée en Belgique.

L'allégorie féminine de l'hymne belge ne sera coulée dans le bronze et érigée à Bruxelles en 1930 seulement, pour célébrer dignement le centenaire de sa création comme celui de l'Indépendance du pays. La même œuvre, mais en plâtre donc provisoire, avait été dressée en novembre 1918 sur la fameuse GrandPlace de la capitale.

Plus tard un peintre russe installé en France depuis 1926, Rostislas Loukine (1904-1988), allait souvent en Belgique pour exposer des œuvres, avec son compatriote franco-russe plus illustre, Nicolas de Staël. Dans la cité frontalière de Werviq, il réalisa, sans doute en 1950, une aquarelle «tachiste» sur le thème des trois couleurs du drapeau belge [Figure 9]. On y voit le défilé pittoresque et patriotique d'une fanfare de fantaisie jouant sans doute la Brabançonne, sur fond bien reconnaissable du clocher de l'église locale consacrée à Saint-Médard.

Ajoutons à propos des créations artistiques emblématiques que c'est Folon, modeste et généreux artiste belge qui, sans demander aucun droit d'auteur, offrit à la France en 1989 le très inspiré et réussi logo tricolore du Bicentenaire de la Révolution française [Figure 10] orné de trois oiseaux figurant la devise républicaine, autre «triade»:

Trois oiseaux libres traversent nos pensées. Trois oiseaux aux couleurs de l'aube s'envolent dans l'espace. Trois mots aux couleurs du temps sont liés pour toujours. Liberté, égalité, fraternité. Mémoire de la Révolution française [texte rédigé par Folon en 1988-89 pour être publié en plusieurs langues]. ${ }^{9}$

9 BICENTENAIRE de la Révolution Française. Document Philatélique Officiel édité par le Administration de Postes et Télécomunications pour le Musée de la Poste et tiré sur la presse de l'Imprimerie de Timbres-Postes. 1989. 


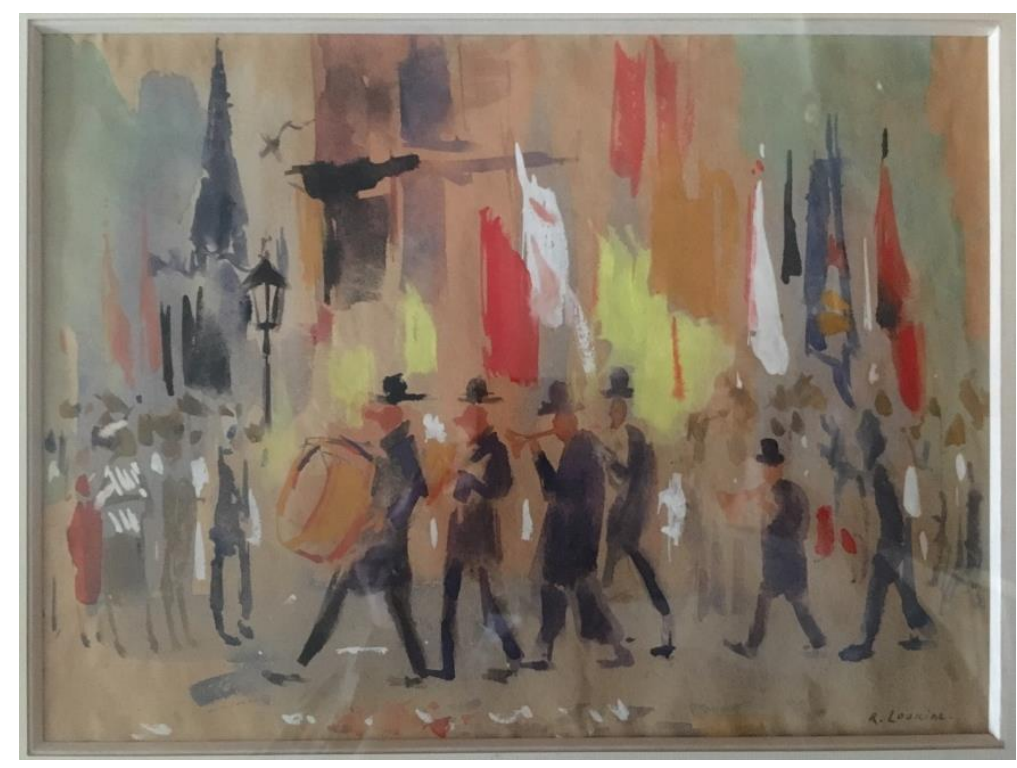

Figure 9:

Rostislas Loukine: Sans titre (au tricolore belge), c. 1950. Aquarelle. Collection privée.
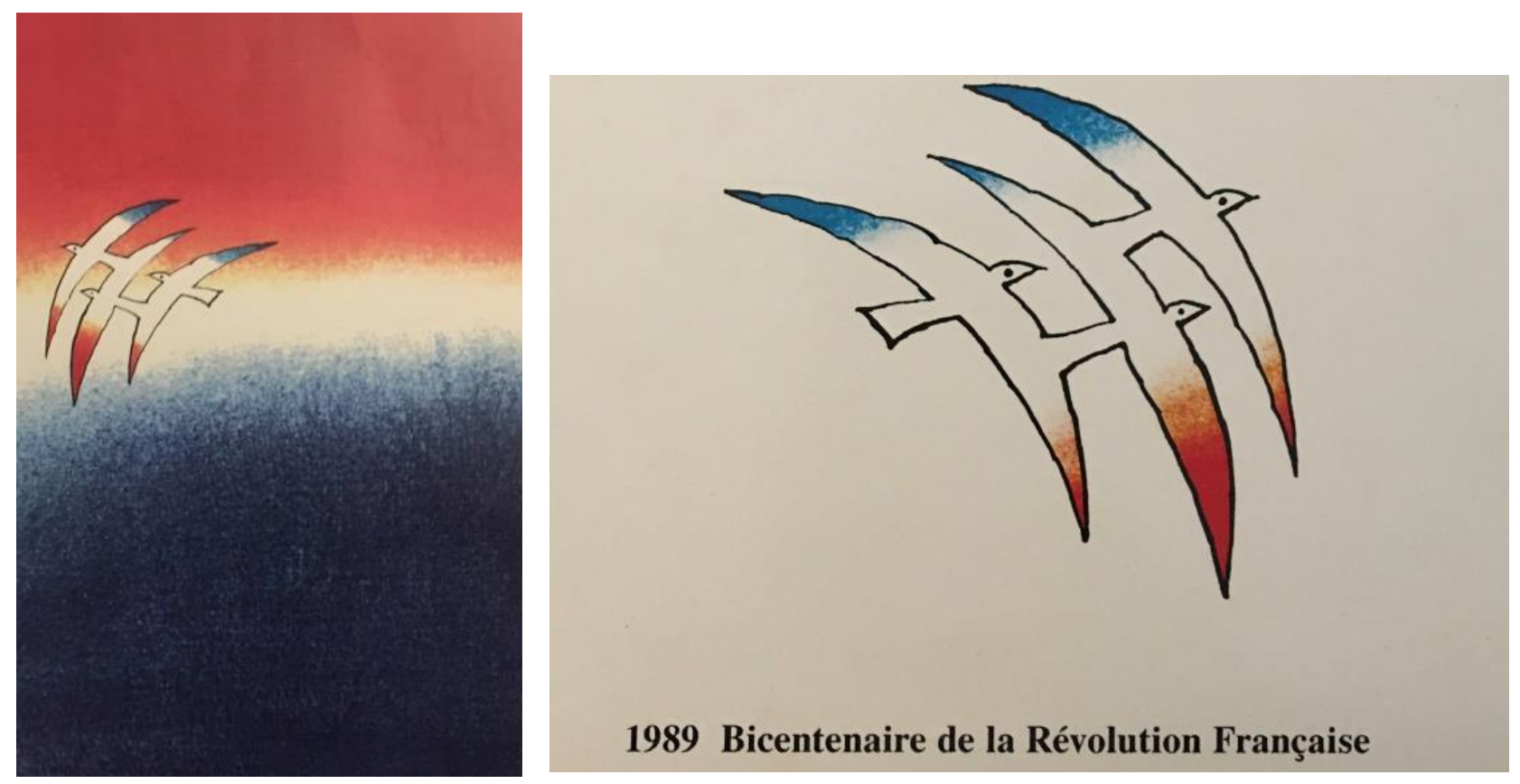

Figure 10: Jean-Michel Folon : Les Oiseaux, 1989. Divers supports et techniques. 


\section{Football, Marseillaise et Belgique}

On a généralement oublié le rôle indirect mais essentiel joué par la Belgique dans l'entrée, ou le retour, de la Marseillaise sur les stades lors de compétitions internationales. Depuis sa trop forte « instrumentalisation » dans l'univers du sport par le régime de Vichy entre 1940 et 1944, la Marseillaise était mal perçue en France sur les stades, phénomène fréquent dans tout pays ayant été soumis à un régime autoritaire «patriotique». Pourtant dans un contexte sportif franco-belge, le 18 mars 1959, éclate une fulgurante Marseillaise en action, vrai «rebond de la Marseillaise». C'était à Reims lors d'un match de football de la coupe d'Europe des clubs champions (dite depuis 1958 coupe d'Europe de l'UEFA) qui opposa le Stade de Reims au Standard de Liège. Le club champion de France avait momentanément perdu son meilleur joueur, Raymond Kopa, parti au Real Madrid (1957/1959), mais il restait sur place une très belle équipe (... bien que battue plus tard en finale de la même coupe précisément par ce Real Madrid).

Au match-aller, le 4 février 1959 en Belgique, le Standard de Liège l'avait emporté par 2 buts à o. II fallait donc au Stade de Reims gagner avec un écart de trois buts pour poursuivre sa route dans cette compétition européenne. Le 18 mars 1959, le match-retour commença mal, sans un seul but marqué dans la première mi-temps et la seconde était bien entamée, seconde au début de laquelle un joueur rémois avait même manqué un penalty. Soudain un spectateur français se dressa dans les gradins, entonnant une vibrante Marseillaise reprise avec fougue et ferveur par tout le public français. Ce fut précisément après cette réaction enflammée que, dans les minutes qui suivirent, Michel Piantoni et Just Fontaine marquèrent successivement les trois buts nécessaires, dont le troisième à la $88^{\mathrm{e}}$ minute, à deux minutes seulement de la fin du temps réglementaire, face à des joueurs liégeois médusés, pétrifiés, qui n'avaient donc marqué aucun but ce jour-là. Le commentaire du journaliste sportif Georges Briquet fut enthousiaste : «Nous avons vécu des moments extraordinaires. Les Français ont chanté la Marseillaise avec une foi qu'on ne leur croyait plus !». In extremis, l'hymne martial avait galvanisé les joueurs français bientôt vainqueurs comme autrefois les soldats français à Jemmapes : « La Marseillaise ailée et volant dans les balles», du poème «Ô soldats de l'an deux! » dans Les Châtiments de Victor Hugo (1853). ${ }^{10}$

Depuis lors, ou à nouveau, la Marseillaise retentit souvent dans les stades, avec parfois des dégâts collatéraux, des rejets «sacrilèges » mais là il ne s'agit pas d'une histoire belge ni franco-belge. Ce retour «intrusif » de la Marseillaise en 1959 sur les stades reste un événement mémorable... et bien oublié, sauf dans certains milieux spécialisés du sport ou de la diplomatie !n

\footnotetext{
${ }^{10}$ HUCO, Victor. Ô soldats de l'an deux! In : idem. Les Châtiments. Paris : Gallimard, 1984 [1 1 ère édition en 1853].

${ }^{11}$ Ce match est décrit sur internet à la rubrique Coupe d'Europe 1958-1959 des clubs champions, Standard de Liège - Stade de Reims. Disponible à : http://www.mondedufoot.fr/resume/champions-league-1958-1959-viertelfinale-stade-reims-standard-liege/. Accès à : 17 nov .
} 


\section{Familiarité avec la Marseillaise}

Les Belges, c'est évident, connaissent bien, voire même trop bien, l'hymne français, certains à cause de souvenirs scolaires portant sur la plus que bicentenaire bataille de Jemmapes. On rapporte encore une autre savoureuse histoire sportive franco-belge qui a été vérifiée sur place par la presse française, par la Voix du Nord. Un club belge de football, certes modeste car classé dans la troisième division, fait entonner la Marseillaise par son public chaque fois qu'il gagne un match à domicile. C'est le Royal Excelsior Virton, de la petite ville de Virton dans les Ardennes belges, à une trentaine de kilomètres au nord de Longwy. Cette coutume «sonore », que l'on retrouve dans d'autres clubs à travers le monde, par exemple en Espagne, en Italie et jusqu'aux antipodes, aurait été lancée à Virton pour célébrer un joueur français engagé par le club dans les années 1980 et heureux responsable de victoires fréquentes. Mais en Belgique, certains vont parfois au-delà.

Ainsi le 21 juillet 2007, jour de fête nationale belge, le très probable futur Premier ministre, chargé de la formation du nouveau gouvernement, Yves Leterme, président du parti démocrate-chrétien flamand, homme politique important, influent, se voyait-il demander par une radio locale de vouloir bien chanter en direct les premières mesures de la Brabançonne. Avec un sourire il répondit en entonnant, dans le micro allumé qu'on lui tendait, un surprenant «Allons enfants de la patrie, le jour de gloire est arrivé ! ». Sa méprise ou sa conduite malicieuse ne pouvait pas traduire le désir, inexistant en Flandre, d'une fusion de la Belgique et de la France ; il s'agissait plutôt de l'effet, en l'occurrence malvenu ou mal reçu, du caractère très présent et familier de la Marseillaise « outre-quiévrain »-comme disent volontiers les chroniqueurs sportifs. A moins que cet homme politique de premier plan n'ait désiré tout bonnement surprendre et séduire ses concitoyens par un humour décalé et ravageur, typiquement belge ${ }^{12}$.

Les Belges, voisins et néanmoins amis de la France, ont si souvent rencontré, voire entonné, la Marseillaise depuis Jemmapes, fin 1792, qu'ils ont presque fini par l'assimiler à un élément de leur patrimoine national, certes marginal par rapport à la Brabançonne, ou à y voir une ballade de leur folklore musical.

\footnotetext{
2020. Ces divers événements franco-belges se retrouvent sur un document télévisuel de la Fédération française de football datant de 1959, ainsi que dans une correspondance reçue de M. Jean-Claude Richard, diplomate français fin connaisseur d'événements sportifs internationaux. Nous le remercions ici sincèrement.

${ }^{12}$ L'incident du 21 juillet 2007, qui n'a pas nui à la carrière politique de son protagoniste, fut abondamment rapporté dans la presse belge et française de l'époque.
} 